03

\title{
Влияние внешнего электрического поля на оптический разряд в скоростном потоке
}

\author{
(C) В.Н. Зудов, ${ }^{1}$ А.В. Тупикин ${ }^{2}$ \\ ${ }^{1}$ Институт теоретической и прикладной механики им. С.А. Христиановича СО РАН, \\ 630090 Новосибирск, Россия \\ ${ }^{2}$ Институт теплофизики им. С.С. Кутателадзе СО РАН, \\ 630090 Новосибирск, Россия \\ e-mail: zudov@itam.nsc.ru
}

Поступило в Редакцию 25 августа 2021 г.

В окончательной редакции 6 октября 2021 г.

Принято к публикации 8 октября 2021 г.

Экспериментально изучено влияние воздействия электрического поля на плазму оптического разряда в дозвуковом и сверхзвуковом потоках воздуха. Наличие слабого электрического поля практически не влияет на размеры плазменного образования, но вне зависимости от конфигурации силовых линий и полярности прикладываемого напряжения приводит к снижению вероятности реализации оптического пробоя. В эксперименте показано, что плазма, создаваемая сфокусированным лазерным излучениям, очень чувствительна к наличию электрического поля. При подаче на кольцевые электроды напряжения свыше $22 \mathrm{kV}$ в потоке формировались мощные квазистационарные стримеры. Наличие плазмы оптического разряда позволило создать электрический разряд в полях с напряженностью ниже порога пробоя среды. Изучены эффект тушения и процессы развития оптического разряда в зависимости от скорости и характеристик электрического поля. Наблюдалось тушение оптического разряда при подаче напряжения $22 \mathrm{kV}$ и выше. Несмотря на сохранение геометрических размеров оптического разряда, высокотемпературная область в потоке может быть увеличена за счет электрических стримеров. Это ведет к увеличению подводимой в поток энергии, и тем самым позволяет инициировать горение и стабилизировать пламя при более высоких скоростях потока.

Ключевые слова: экспериментальное моделирование, лазерное излучение, оптический пробой, электрическое поле, электрический разряд, до- и сверхзвуковой воздушный поток.

DOI: 10.21883/JTF.2022.02.52009.244-21

\section{Введение}

Когда интенсивное лазерное излучение фокусируется в атмосфере, воздух ионизируется из-за многофотонной или туннельной ионизации, то образуются один или несколько плазменных каналов с низкой проводимостью [1]. Особенности филаментации лазерного луча, такие как распространение на большие расстояния $[2,3]$ и пробой в воздухе [4], привели к множеству потенциальных технологических и научных приложений. Лазерная плазма использовалась в качестве источников терагерцового и рентгеновского излучения для спектроскопических и медицинских приложений [5]. Были разработаны чувствительные методы измерения ультрафиолетового излучения с использованием оптического пробоя газа [6,7].

Реализация совместного оптического и электрического разрядов также находит применение в различных научных областях. Например, в [8-13] комбинация электрического поля с лазерным пробоем применялась для формирования лазерного триггерного переключателя искрового разрядника. Разработанная схема устройства основана на снижении напряжения пробоя разряда за счет формирования плазмы лазерного пробоя в межэлек- тродном пространстве [8]. Заметим, что при создании индуцированного лазером электрического пробоя, длина стримеров значительно увеличивается [14]. Это может быть использовано для снижения пороговых характеристик зажигания и горения легковоспламеняющейся смеси [12]. В работе [13] плазма оптического разряда создавалось в воздухе низкого давления ( $\sim 20$ Torr $)$ при фокусировке излучения $\mathrm{CO}_{2}$-лазера, где было показано, что образованная лазерным пробоем плазма может быть подавлена внешним электрическим полем. Следует отметить, что без приложения электрического поля оптический пробой реализовывался регулярно (практически со 100-\% вероятностью). В электрическом поле напряженностью выше $600 \mathrm{~V} / \mathrm{cm}$ оптический пробой в значительной степени подавлялся (частота пробоя уменьшалась). Дальнейшее увеличение напряженности электрического поля вело к улучшению условий реализации оптического разряда (частота пробоя возрастала) вплоть до начального состояния. Это свидетельствует о том, что существует экстремум по параметрам электрического поля при реализации в нем оптического разряда.

Для лазерного излучения с энергией квантов ниже потенциала ионизации среды механизм оптического пробоя связан с развитием электронной лавины [1]. 
В отсутствие внешних полей процессом, ответственным за потери электронов в области фокусировки луча, является диффузия, которая может быть значительной при низких давлениях. Наложение внешнего поля увеличивает отток электронов, повышая пороговую интенсивность излучения при оптическом пробое. Выше некоторого значения напряженности электрического поля возникает дополнительный механизм рождения свободных электронов, обеспечивая более высокую скорость развития области лазерного пробоя. Возможно, что именно с этим связано существование экстремума по параметрам электрического поля при реализации в нем оптического разряда.

В [14] при атмосферном давлении было показано изменение порога пробоя путем наложения электрического поля на область фокусировки лазера $\mathrm{Nd}$ : YAG (длиной волны $1064 \mathrm{~nm}$ ) в наносекундном временном масштабе. При этом все время происходило увеличение пороговой интенсивности излучения при пробое среды, не достигая экстремума в зависимости от напряженности внешнего электрического поля. Аналогичный результат получен в работе [15], где приложение внешнего электрического поля к фокусному объему газовой ячейки высокого давления вело только к увеличению пороговой интенсивности излучения при оптическом пробое. Авторы считают, что это связано с электростатической очисткой газа (от частиц, являющихся очагами пробоя) и за счет удаления свободных электронов из области фокусировки между лазерными импульсами. В экспериментах с длиной волны лазерного излучения $1.06 \mu \mathrm{m}$ при длительности 200 ps и интервалом между импульсами $7.5 \mathrm{~ns}$ было установлено, что электростатическая очистка эффективно гасит оптический пробой при $20 \mathrm{~atm}$ и максимальной интенсивности единичного импульса $140 \mathrm{~J} / \mathrm{cm}^{2}\left(\sim 0.7 \mathrm{TW} / \mathrm{cm}^{2}\right)$. При этом воздействие внешнего электрического поля на фокальный объем создает дополнительный механизм потерь (дрейф), который помогает снизить плотность свободных электронов ниже пороговой, требуемой для инициирования оптического пробоя.

В работах $[14,15]$ не наблюдалось экстремума по напряженности электрического поля при реализации в нем оптического разряда, возможно потому, что эти эксперименты были проведены при давлениях, существенно превышающих давление в [13]. Заметим, что экспериментальная зависимость пороговой интенсивности лазерного излучения от давления среды имеет экстремум при осуществлении оптического разряда в неоне и аргоне, как показано в [11].

В настоящей работе изучалось влияние внешнего электрического поля на плазму оптического разряда в скоростном потоке, при статических давлениях близких к атмосферному. Воздействие на плазму осуществлялось стационарным электрическим полем напряженностью до $24 \mathrm{kV} / \mathrm{cm}$. Наблюдались явления, связанные с затуханием оптического разряда. Особое внимание уделялось условиям, при которых была возможности создания комбинации оптического и электрического разрядов.

\section{1. Экспериментальная установка}

Для создания плазмы оптического пульсирующего разряда применялся электроразрядный $\mathrm{CO}_{2}$-лазер ЛОК-ЗСГУ (разработка Института лазерной физики СО PAН), который обеспечивал импульсно-периодический режим работы с частотой следования импульсов до $60 \mathrm{kHz}$ при средней мощности порядка $1.0 \mathrm{~kW}$. Форма импульса падающего излучения регистрировалась ИК-фотоприемником ФД-511-2 (спектральный диапазон до $11 \mu \mathrm{m})$. Излучение плазмы оптического разряда фиксировалось на фотоприемник ФД-256, диапазон 0.4-1.1 $\mu \mathrm{m}$. В экспериментах лазер работал в пакетном режиме (3-6 импульсов) с несущей частотой $30-40 \mathrm{kHz}$, частота следования пакетов была $5-7 \mathrm{kHz}$. Излучение $\mathrm{CO}_{2}$-лазера распространялось поперек потока и фокусировалось линзой из $\mathrm{ZnSe}$ между электродами на оси струи на заданном расстоянии от среза сопла, которое равнялось $14 \mathrm{~mm}$ и в ходе опытов изменялось незначительно. В экспериментах применялись линзы с различным фокусным расстоянием $(f=63,95,125 \mathrm{~mm})$. На рис. 1 представлена схема эксперимента.

Воздух подавался в форкамеру и истекал из сверхзвукового сопла в затопленное пространство (в свободную атмосферу). Внутренний диаметр форкамеры $80 \mathrm{~mm}$, длина $95 \mathrm{~mm}$. Для формирования потока использовалось коническое сопло с угловой точкой, изготовленное из капролона. Диаметры критического и выходного сечений равны 15.5 и $20 \mathrm{~mm}$ соответственно. Расстояние между указанными сечениями $25 \mathrm{~mm}$. Максимальное давление в форкамере было $P_{0}=0.8 \mathrm{MPa}$ при температуре $T=290 \mathrm{~K}$.

Для определения газодинамической структуры потока применялась теневая схема со щелью и плоским ножом. В качестве источника подсветки использовался искро-

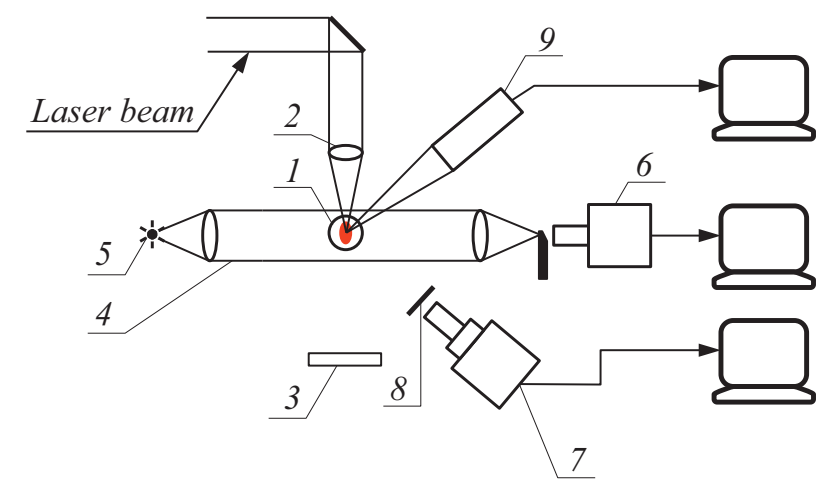

Рис. 1. Схема эксперимента: 1 - объект наблюдения; 2 - линзы; 3 - поглотитель; 4 - шлирен-система; 5 - источник света; 6 - фотокамера; 7 - высокоскоростная камера; 8 - интерференционный фильтр; 9 - CCD-камера. 


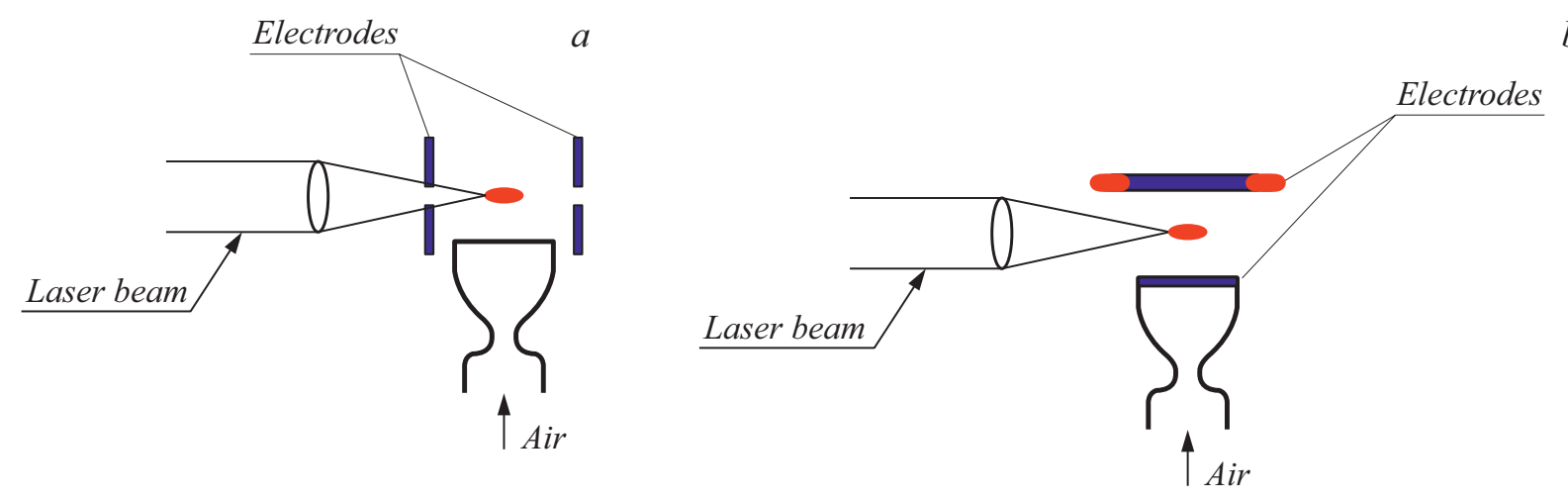

$b$

Рис. 2. Схема расположения электродов и лазерного луча: $a-$ электрическое поле вдоль луча; $b-$ поле поперек луча.

вой электрический разряд в аргоне с длительностью свечения $1 \mu \mathrm{s}$. Визуализация течения теневым методом дала возможность надежно определить границы существования зоны оптического разряда в потоке, а также пространственные масштабы тепловых неоднородностей смещающихся вниз по потоку от области пробоя.

В опытах применялись различные конфигурации электродов (рис. 2): плоские электроды - электрическое поле вдоль лазерного луча $(a)$; кольцевые электроды поле вдоль потока и поперек луча $(b)$. Была опробована также конфигурация, где вместо плоских пластин были установлены кольцевые электроды.

На рис. 2, а приведена схема для плоскопараллельных пластин, расстояние между которыми было $3 \mathrm{~cm}$, расположенных за границами истекающей струи. В электродах имелись отверстия диаметром $5 \mathrm{~mm}$ для прохождения лазерного луча, фокусируемого на оси воздушного потока.

На рис. 2, $b$ показана схема эксперимента с продольным по потоку электрическим полем. Электрическое поле создавалось двумя кольцевыми электродами. Величина напряжения на электродах варьировалась от 6 до $30 \mathrm{kV}$. В ходе опытов полярность могла меняться.

В экспериментах применялось три источника питания с напряжением до 2 , до 6 и до $24 \mathrm{kV}$. Первый источник был использован для получения слабого электрического поля. Остальные два для определения границы совместного существования оптического разряда и электрических стримеров. Первоначально для организации электрического поля поперек воздушного потока использовались электроды в виде плоских пластин. Применение кольцевых электродов в той же схеме дало улучшение условий создания электрических разрядов (стримеров).

\section{2. Экспериментальные результаты и обсуждение}

На рис. 3 представлены кадры теневой регистрации при оптическом пробое в отсутствие электрического поля: $a-$ в покоящейся среде, $b-$ в сверхзвуковой струе. На рис. 3, $a$ хорошо видна ударная волна, распространяющаяся из области энергоподвода по покоящейся среде. Размеры плазменной области составляли 5-7 mm. Вначале ударная волна повторяет форму плазменного образования, а затем принимает форму окружности. На рис. $3, b$ видна структура сверхзвуковой струи при нерасчетном истечении в атмосферу, область фокусировки лазерного луча находится выше конического скачка уплотнения. Наблюдаемая структура включает в себя сверхзвуковую затопленную струю с характерными скачками уплотнения, плазмоид, тепловые неоднородности в следе за ним. В пространстве за границей струи наблюдаются периодические звуковые возмущения, частота которых соответствует частоте следования лазерных импульсов, рис. $3, b$.

На рис. 4 показаны структура дозвукового течения и оптический разряд с применением плоских электродов для трех случаев: без электрического поля (рис. 4,a); с электрическим полем $U=6 \mathrm{kV}$, положительный электрод справа (рис. $4, b$ ) и положительный электрод слева (рис. 4,c). Заметим, что во всех случаях основные элементы структуры течения мало отличаются. При этом в потоке образуется ограниченная область плазмы, о чем свидетельствует возникновение ударных волн эллиптической формы. Размеры плазменной области составляют $\sim 3 \mathrm{~mm}$ (при диаметре пятна фокусировки $0.2 \mathrm{~mm}$ ), за которой развивается периодический тепловой след. Структура следа зависит от частоты следования лазерных импульсов. Эксперимент был проведен при частоте следования лазерных импульсов $32 \mathrm{kHz}$, а давление в форкамере превышало атмосферное на 0.18 atm. Значительного влияния электрического поля на структуру течения не наблюдается.

В дозвуковом потоке при низкой напряженности электрического поля вне зависимости от полярности наблюдалось ухудшение условий существования оптического разряда (снижение вероятности пробоя). То есть фиксировалось снижение количества откликов образующейся плазмы оптического разряда при наложении электрического поля. Возможно, это связано с электростатической очисткой области фокусировки от посторонних частиц, 


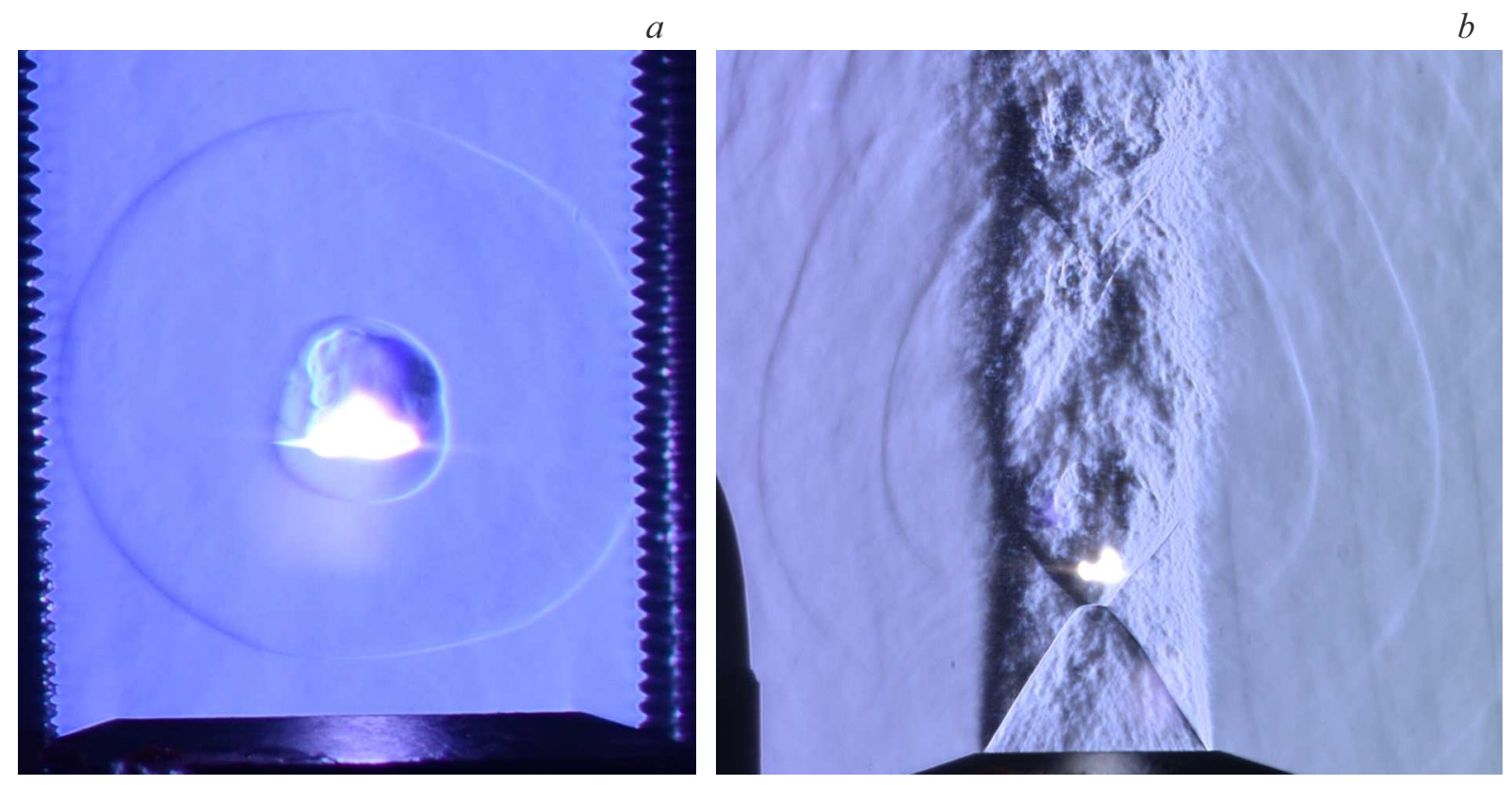

Рис. 3. Теневая регистрация оптического разряда в отсутствие электрического поля: $a-$ без потока; $b-$ в сверхзвуковом потоке $\left(P_{0}=0.66 \mathrm{MPa}\right)$.

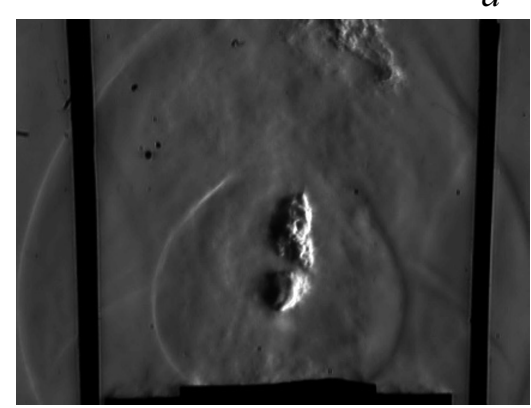

$b$

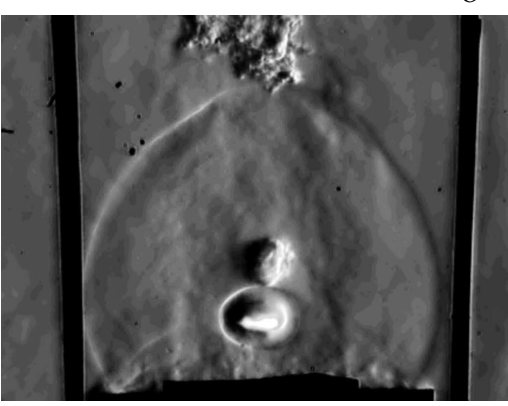

c

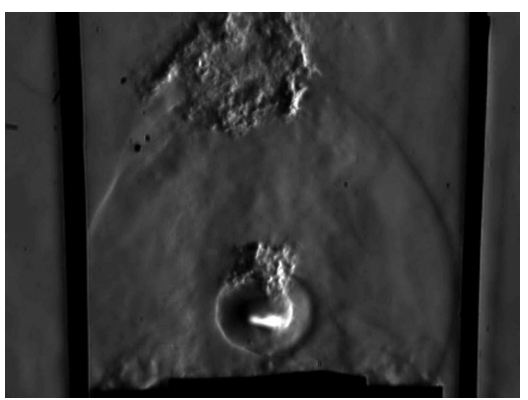

Рис. 4. Теневая регистрация для случая плоских электродов в дозвуковом потоке: $a-$ в отсутствие электрического поля; $b$ - поле $(6 \mathrm{kV})$ направлено слева направо; $c$ - поле направлено справа налево.

являющихся центрами развития пробоя, и увеличением оттока электронов из области фокусировки под воздействием электрического поля.

Слабое электрическое поле (до $11 \mathrm{kV}$ ) практически не влияет на размеры плазменного образования вне зависимости от полярности. При высоких напряжениях смена полярности поля не приводила к значительным изменениям формы плазменного образования, а при наличии стримеров - и его размеров. В экспериментах форма и предельные характеристики электрического пробоя зависели от конфигурации электродов, приложенного напряжения и скорости воздушного потока.

В отсутствие электрического пробоя смена полярности на кольцевых электродах также не ведет к значительным изменениям в структуре течения (рис. 5). Увеличение напряженности поля в такой конфигурации электродов приводило к реализации комбинированного оптического и электрического разрядов. На рис. 5, отчетливо виден стример от среза сопла (анода) к области оптического пробоя, при этом выше плазменного образования, т.е. в следе оптического разряда, стримерных каналов не наблюдается.

В отдельной серии опытов было рассмотрено влияние перепада давления $(\Delta p)$ между форкамерой и окружающей средой на формирование оптического разряда. Частота следования лазерных импульсов была $f=32 \mathrm{kHz}$. Исследования проводились в диапазоне перепада $\Delta p$ от 0.016 до $0.6 \mathrm{~atm}$. Для создания внешнего электрического поля применялись кольцевые электроды. В результате установлено, что при $\Delta p=0.6 \mathrm{~atm}$ существовал только оптический разряд (рис. $5, b$ ), а при $\Delta p=0.016 \mathrm{~atm}$ в дополнение к оптическому пробою происходил электрический пробой (рис. 5,c). При напряжении на электродах $18.5 \mathrm{kV}$ ток был $0.8 \mathrm{~mA}$, при 
$a$

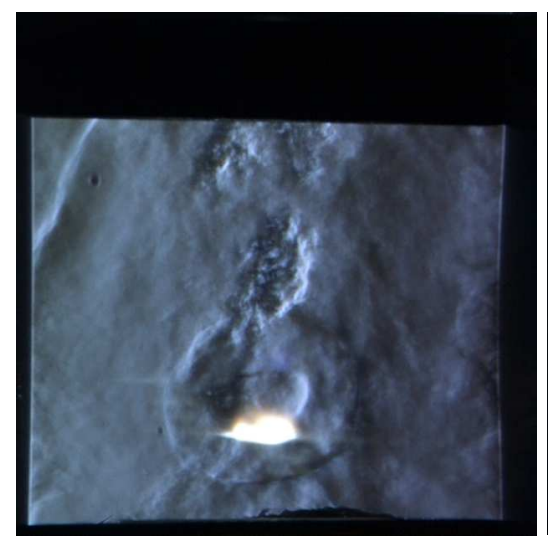

$b$

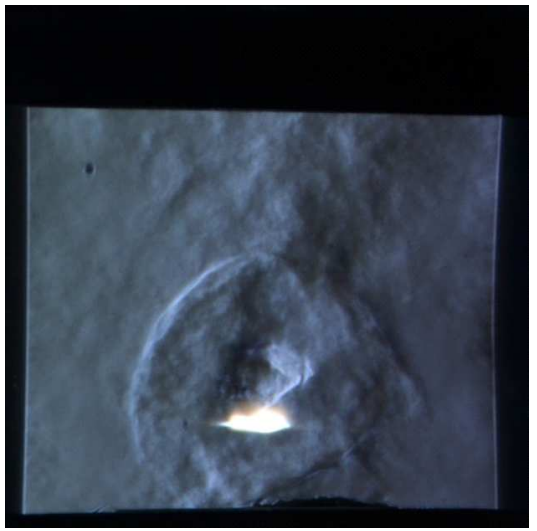

C

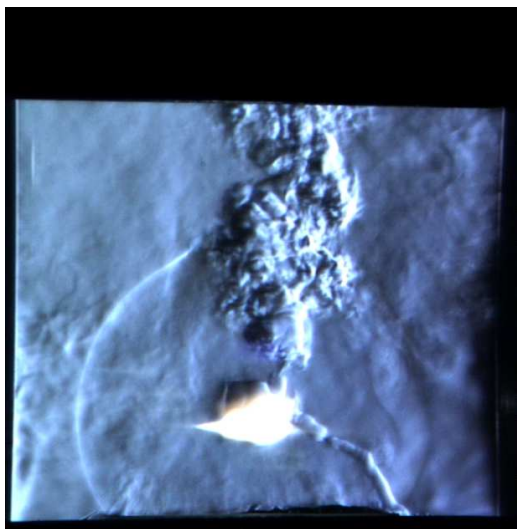

Рис. 5. Теневая регистрация для случая кольцевых электродов (анод сверху) в дозвуковом потоке: $a-$ без электрического поля $(\Delta p=0.6 \mathrm{~atm}) ; b-U=18.5 \mathrm{kV}(\Delta p=0.6 \mathrm{~atm}) ;$ и $c-U=18.5 \mathrm{kV}, \Delta p=0.016 \mathrm{~atm}$.

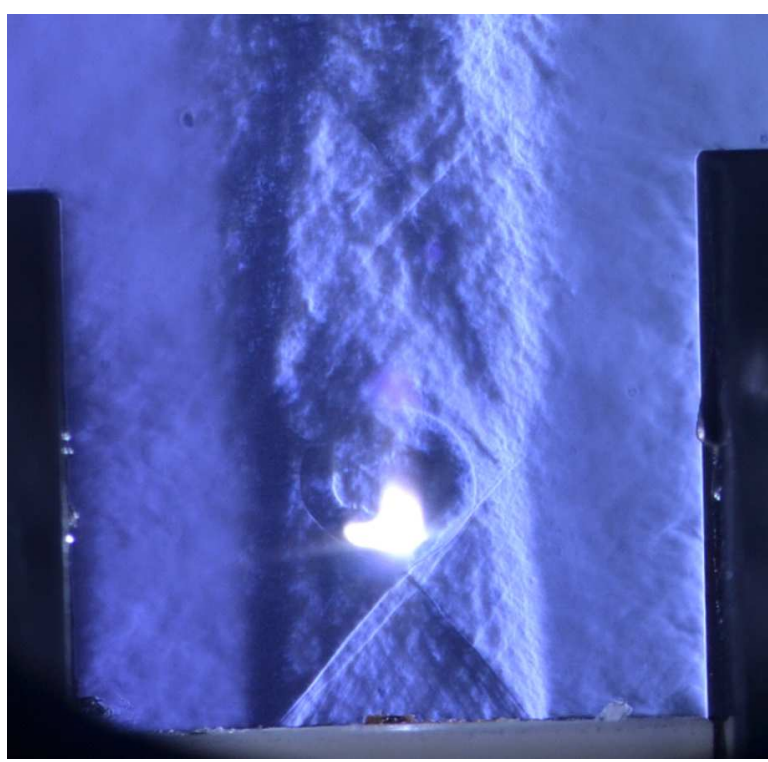

$b$

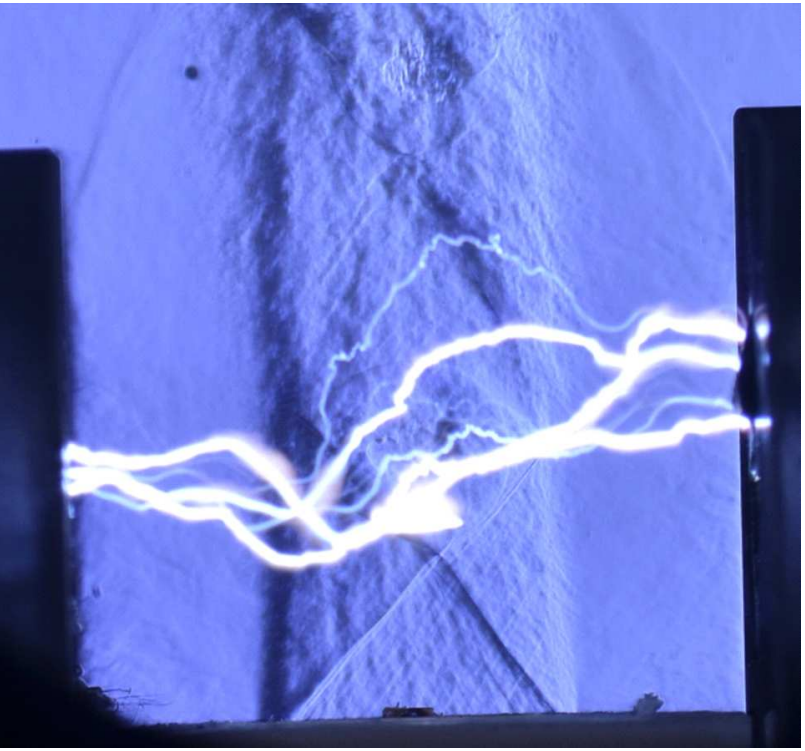

Рис. 6. Оптический разряд в сверхзвуковой струе при наличии электрического поля (полное давление $P_{0}=0.5 \mathrm{MPa}, U=22 \mathrm{kV}$ ): $a-$ без стримеров, $b-$ со стримерами.

электрическом пробое наблюдалось падение напряжения до $17 \mathrm{kV}$ и снижение тока до $0.6 \mathrm{~mA}$.

Различные положения области электрического пробоя во времени свидетельствуют о протекании нестационарных процессов. Наблюдается зависимость вероятности возникновения электрического пробоя от давления. Установлено, что при $\Delta p=0.06 \mathrm{~atm}$ происходят редкие электрические пробои, а в диапазоне перепада давлений $\Delta p=0.036-0.06 \mathrm{~atm}$ они отсутствуют.

Была опробована также конфигурация, когда плоские пластины были заменены на кольцевые электроды. Воздушная струя истекала в затопленное пространство со сверхзвуковой скоростью (расчетное число Маха $\mathrm{M}=2$ ). Структура сверхзвуковой струи с оптическим и комбинированным (оптический плюс электрический) разрядами при одинаковых условиях истечения представлена на рис. 6. При этом возможна реализация двух сценариев: без стримеров электрического разряда и с электрическим пробоем среды. Положение и количество стримеров может разниться от опыта к опыту, подчеркивая стохастичность процесса развития стримерных каналов. Стримеры электрического разряда создают дополнительное тепловыделение, и поэтому комбинированный разряд создает область теплоподвода, значительно превышающую размеры оптического пробоя. Режим существования такого плазменного образования в струе и вне ее приближается к квазистационарному, что необходимо для инициирования и стабилизации горения в высокоскоростном потоке топливовоздушной смеси. 


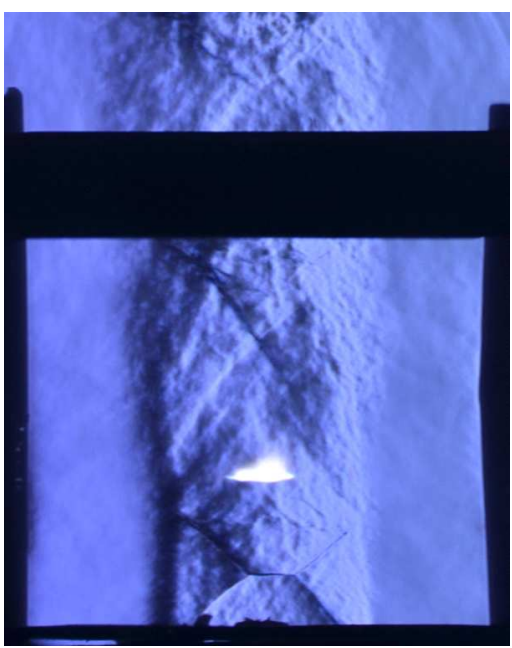

$b$

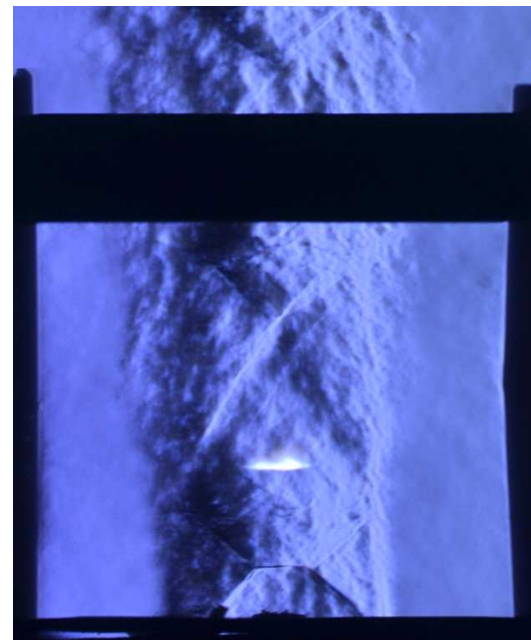

$c$

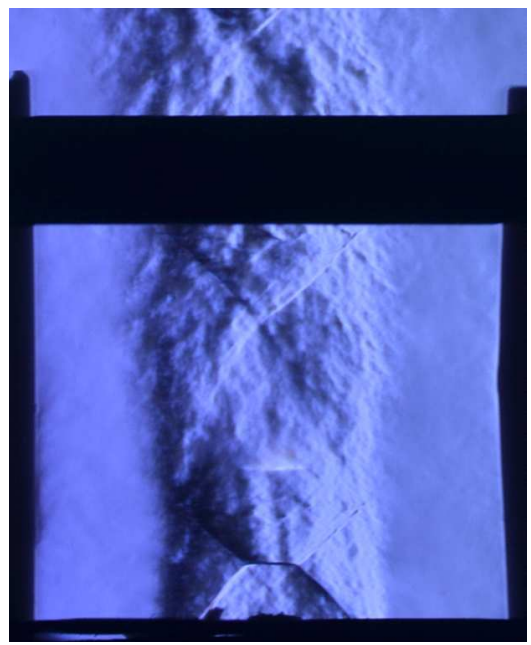

Рис. 7. Тушение оптического разряда при росте напряженности (слева направо) электрического поля, направленного поперек луча $\left(P_{0}=0.3 \mathrm{MPa}, U=11-22 \mathrm{kV}\right)$.
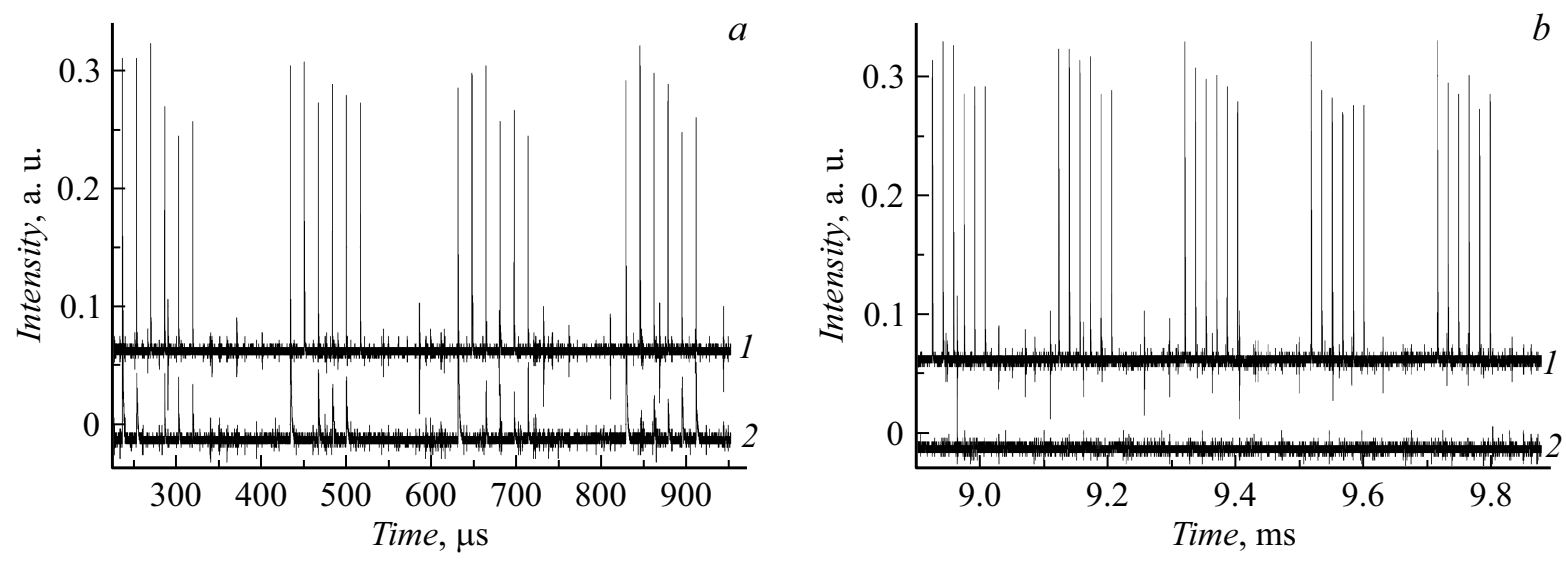

Рис. 8. Фотометрическая регистрация излучения при тушении оптического разряда.

В определенных условиях наблюдается эффект тушения оптического разряда электрическим полем. Затухание оптического разряда в сверхзвуковой струе происходило при постепенном увеличении напряжения на электродах от 11 до $22 \mathrm{kV}$ (рис. 7). Данное явление не зависело от конфигурации электрического поля, и наблюдалось в поле, направленном как по потоку, так и вдоль лазерного луча.

В качестве примера на рис. 7 показано влияние роста напряжения на кольцевых электродах на интенсивности свечения из области пробоя. Излучение от плазмоида с увеличением напряжения постепенно снижается. Тушение оптического разряда электрическим полем, направленным по потоку, происходило и при дозвуковом истечении струи. Данный эффект наблюдался и при других давлениях $\left(P_{0}=0.4\right.$ и $\left.0.5 \mathrm{MPa}\right)$. Монотонное снижение напряженности электрического поля ведет к восстановлению оптического разряда до своего невозмущенного состояния (без поля).
Таким образом, изменяя параметры внешнего электрического поля, можно управлять плазмой оптического разряда, включая его полное тушение полем. Эффект тушения связан с отток электронов из области поглощения лазерного излучения.

Представленные выше эффекты тушения подтверждаются регистрацией излучения плазмы оптического разряда. При наложении поля на область фокусировки уменьшалось количество пиков на осциллограмме сигнала от образующейся плазмы. На рис. 8 представлены результаты регистрации интенсивности падающего излучения лазерного импульса (индекс 1) и плазмы оптического разряда (индекс 2). На левой части рисунка приведены данные без поля, а на правой - сигналы после включения поля. До момента времени $\sim 900 \mu \mathrm{s}$ наблюдается регулярный отклик плазмы, после включения поля излучение от плазмы отсутствует. Вероятнее всего, происходит электростатическая очистка области фокусировки от посторонних частиц, являющихся 
центрами развития пробоя, т.е. реализуется ситуация, аналогичная представленной в работе [15]. При этом происходит увеличение скорости оттока электронов из области фокусировки под воздействием электрического поля.

\section{Заключение}

Разработана и апробирована методика оптических измерений для регистрации структуры течения при взаимодействии сверхзвукового потока с электрическим и оптическим разрядами.

Рассмотрено два режима влияния внешнего электрического поля на плазму оптического разряда: электрическое поле направлено по воздушному потоку либо поперек воздушного потока. Были использованы плоские и кольцевые электроды.

Экспериментально показана возможность одновременного существования оптического и электрического разрядов.

Показано, что изменяя параметры внешнего электрического поля, можно управлять плазмой оптического разряда, включая ее полное тушение.

Обнаружено два режима совместного существования плазмы оптического и электрического разрядов. В первом электрический разряд располагался между плазмой оптического разряда и одним из электродов. Во втором режиме электрический разряд располагался между электродами с одновременным существованием оптического разряда.

Эффект от реализации в потоке совместно оптического и электрического разрядов приведет к дополнительному энергетическому воздействию на структуру течения, и тем самым может улучшить условия для инициирования горения и стабилизации топливных смесей, приближаясь к квазистационарному режиму энергетического воздействия на сверхзвуковое течение.

\section{Финансирование работы}

Работа выполнена при частичной финансовой поддержке Российского фонда фундаментальных исследований (грант № 19-08-00304).

\section{Конфликт интересов}

Авторы заявляют, что у них нет конфликта интересов.

\section{Список литературы}

[1] Ю.П. Рйзер. Лазерная искра и распространение разрядов (Наука, М., 1974)

[2] Э.И. Асиновский, Л.М. Василяк, О.П. Нестеркин. ТВТ, $35(6), 858$ (1997).

[3] О.Б. Данилычев, С.А. Тульский. ЖТФ, 48, 2040 (1978).
[4] S.B. Leonov, A.A. Firsov, M.A. Shurupov, J.B. Michael, M.N. Shneider, R.B. Miles, N.A. Popov. Phys. Plasmas, 19, 123502 (2012). https://doi.org/10.1063/1.4769261

[5] A. Houard, Y. Liu, B. Prade, V.T. Tikhonchuk, A. Mysyrowicz. Phys Rev. Lett., 100, 255006 (2008).

[6] D.W. Hahn, N. Omenetto. Appl. Spectrosc., 64, 335A (2010).

[7] D.W. Hahn, N. Omenetto. 66, 347 (2012).

[8] M.J. Kushner, R.D. Milroy, W.D. Kimura. J. Appl. Phys., 58, 2988 (1985).

[9] T. Fujii, A. Zhidkov, M. Miki, K. Sugiyama, N. Goto, S. Eto, Y. Oishi, E. Hotta, K. Nemoto. Chinese J. Phys., 52, 440 (2014). DOI: 10.6122/CJP.52.440

[10] В.Я. Никулин, С.П. Цыбин, А.Е. Гурей. Краткие сообщения по физике ФИАН, 6, 15 (2017).

[11] V. Kumar, R.K. Thareja. J. Appl. Phys., 64, 5269 (1988).

[12] E. Takahashi, S. Sakamoto, O. Imamura, Y. Ohkuma, H. Yamasaki, H. Furutani, K. Akihama. J. Phys. D Appl. Phys., 52, 485501 (2019).

[13] J. Tulip, H. Seguin. Appl. Phys. Lett., 23, 135 (1973).

[14] E. Takahashi, S. Kato. OSA Continuum., 3, 3030 (2020). DOI: $10.1364 /$ OSAC.399530

[15] R.A. Mullen, J.N. Matossian. Opt. Lett., 15, 601 (1990). 